Artículo Original

\title{
Correlación entre el cociente proteinuria/creatininuria en una orina al azar y la proteinuria de 24 horas
}

Correlation between the random urine protein-creatinine ratio and 24-hour proteinuria

\author{
Autores: Yngrid Margarita González Cascán ${ }^{1}$, Estela Torres de Taboada ${ }^{2}$
}

Artículo recibido: 3 enero 2015 Artículo aceptado: 26 enero 2015

\section{Resumen}

Introducción: la cuantificación de proteínas en orina es un estudio que evalúa la afectación renal por ciertas enfermedades. Su medición puede realizarse también a través del cociente proteinuria/creatininuria. Objetivo: determinar la correlación entre el cociente proteinuria/creatininuria y la proteinuria de 24 horas. Metodología: se realizó un estudio descriptivo observacional, prospectivo con componente analítico de corte transverso, de muestreo no probabilístico. Se incluyó a 60 pacientes con factores de riesgo de padecer enfermedad renal crónica, que acudieron al Hospital Nacional (Itauguá) en el año 2014. Todos se realizaron análisis de orina de 24 horas y de una muestra de orina al azar para estimar el cociente proteinuria/creatininuria.

Resultados: se observó que existe una correlación muy significativa $(r=0,9 p<0,001)$ entre los valores del cociente de proteinuria/creatininuria en una orina al azar y la proteinuria de 24 horas, con una sensibilidad 94,1\% (IC95\% 79-100), especificidad 100\% (IC95\% 98-100\%), valor predictivo positivo 100\% (IC95\% 96100) y valor predictivo negativo 97,7\% (IC95\% 92-100).

Conclusiones: el cociente proteinuria/creatininuria es útil para detectar proteinuria en rango no nefrótico.

Palabras claves: proteinuria, proteinuria de 24 horas, cociente proteinuria/creatininuria, hipertensión arterial, lupus eritematoso sistémico

\section{Abstract}

Introduction: The quantification of proteins in urine is a study that evaluates kidney involvement in some diseases. The measurement can be made through the urine protein-creatinine ratio. Objective: To determine the correlation between the urine protein-creatinine ratio and 24-hour urine protein. Methodology: A cross-sectional prospective observational descriptive study with analytical component and non-probabilistic sampling was performed. Sixty patients who had risk factors of chronic renal disease and attended the National Hospital (Itauguá) in 2014 were included. Twenty four-hour urine and a random urine sample were analyzed to estimate the protein-creatinine ratio.

Results: A very significant correlation $(r=0.9 p<0.001)$ was observed between the values of the proteincreatinine ratio in a random urine and 24-hour urine protein with a sensitivity of 94.1\% (IC95\% 79-100), specificity of 100\% (IC95\% 98-100\%), positive predictive value of 100\% (IC95\% 96-100) and negative predictive value of $97.7 \%$ (IC95\% 92-100).

${ }^{1}$ Residente de Medicina Interna. Dpto. de Medicina Interna. Hospital Nacional (Itauguá, Paraguay). Facultad de Medicina, Universidad Nacional de Itapúa.

${ }^{2}$ Especialista en Medicina Interna. Dpto. de Medicina Interna. Hospital Nacional (Itauguá, Paraguay).

Autor correspondiente:

Dra. Yngrid Margarita González Cascán

Dirección: Hospital Nacional (Itauguá, Paraguay)

Teléfono: +(595) 972848760

Correo electrónico: ynmargarita@gmail.com 
Conclusion: The protein-creatinine ratio is useful to detect proteinuria in a non-nephrotic range.

Keywords: proteinuria, 24-hour proteinuria, urine protein-creatinine ratio, arterial hypertension, systemic lupus erythematosus

\section{Introducción}

La enfermedad renal crónica es una entidad clínica secundaria a múltiples etiologías, se caracteriza por ser silente en etapas tempranas y, en ausencia de tratamiento adecuado, tiene un curso progresivo que conduce a un fallo irreversible de la función del órgano y requerimiento de tratamiento sustitutivo renal ${ }^{1,2}$. El parámetro que mejor refleja la función renal es el filtrado glomerular, que es dependiente de la masa renal funcionante. Asimismo, la monitorización de las variaciones del filtrado glomerular evalúa la progresión de la enfermedad renal.

Por lo tanto, el filtrado glomerular es una medida directa de la función renal y es reflejo de la masa renal funcionante. Se conocen tres aspectos principales de esta medida:

1- $\quad$ La reducción del filtrado glomerular: se correlaciona con la gravedad de las alteraciones estructurales como la fibrosis tubulointersticial y con la aparición de síntomas cuando disminuye por debajo de $10-15$ $\mathrm{mL} / \mathrm{min}$.

2- $\quad$ La monitorización de las variaciones del filtrado glomerular: delimita la progresión de la enfermedad renal, siendo un potente predictor del tiempo hasta que se inicia el fallo renal y de las complicaciones de la nefropatía crónica.

3- $\quad$ El cálculo del filtrado glomerular: permite la dosificación apropiada de los fármacos excretados por el glomérulo.

La determinación exacta del filtrado glomerular es difícil de realizar, puede ser imprecisa y ser relativamente insensible para detectar precozmente la enfermedad renal. La técnica gold standard, el aclaramiento de inulina, es una técnica laboriosa y prácticamente imposible de llevar a cabo en la clínica habitual, permaneciendo como una herramienta de investigación. La presencia de niveles relativamente bajos de proteínas en orina es un marcador de riesgo precoz de progresión o aparición de enfermedad renal, eventos cardiovasculares e incluso muerte. La American Diabetes Association y la National Kidney Foundation recomiendan valorar la presencia de proteinuria o de albuminuria para detectar la enfermedad renal crónica ${ }^{3}$.

Una gran variedad de individuos tiene un elevado riesgo de presentar enfermedad renal crónica, entre ellos, los pacientes de edad avanzada, historia familiar de enfermedad renal crónica, hipertensión arterial, diabetes mellitus, enfermedades cardiovasculares, reducción de la masa renal, bajo peso al nacer, enfermedades autoinmunes y sistémicas, uso de fármacos nefrotóxicos, entre otros ${ }^{4}$.

\section{Evaluación de la proteinuria}

La excreción de proteínas (de bajo peso molecular, albúmina) depende del tipo de lesión renal. La excreción de cantidades elevadas de albúmina es un marcador sensible de enfermedad renal por diabetes mellitus e hipertensión arterial, también es un marcador de riesgo cardiovascular elevado en este tipo de pacientes y en la población general ${ }^{4}$.

La proteinuria puede tener diversos orígenes:

- Glomerular: por aumento de la filtración de macromoléculas como la albúmina.

- Tubular: proteínas de bajo peso molecular. Estas proteínas más pequeñas se pueden filtrar a través del glomérulo y son casi completamente reabsorbidas en el túbulo proximal. La interferencia con la reabsorción tubular proximal, debido a una variedad de enfermedades tubulointersticiales o incluso algunas enfermedades glomerulares primarias, puede conducir a aumento de la excreción de estas proteínas más pequeñas. 
- Por exceso de producción: también llamada por desbordamiento, se produce por aumento de excreción de proteínas de bajo peso molecular y puede ocurrir por marcada producción de una proteína en particular. Esto es casi siempre debido a las cadenas ligeras de inmunoglobulinas en el mieloma múltiple. El exceso de proteínas filtradas excede la capacidad de reabsorción del túbulo proximal.

En condiciones normales, un individuo sano elimina por la orina entre 40 - 80 mg de proteína por día, de los cuales aproximadamente 10-15 mg corresponden a la albúmina y el resto está formado principalmente por la proteína de Tamm - Horsfall y por pequeñas cantidades de otras proteínas de bajo peso molecular.

La presencia en orina de proteínas de bajo peso molecular ( $\beta 2$-microglobulina, $\alpha 1$-microglobulina, proteína ligada al retinol, entre otras) denota la existencia de enfermedad tubulointersticial. También debe destacarse otro tipo de proteína como la ortostática que aparece solamente cuando el individuo se encuentra de pie, pero es menor a $2 \mathrm{~g} /$ día y afecta sobre todo a niños y adolescentes.

Distintos mecanismos etiopatogénicos están implicados en el aumento de concentración de proteínas en orina y cada uno de ellos se asocia con una proteinuria de características cuantitativas y cualitativas diferentes. La presencia de albúmina en orina expresa daño glomerular, siendo un factor de riesgo en la progresión de la enfermedad renal crónica tanto en adultos como en niños ${ }^{5}$.

La albúmina es la proteína plasmática más abundante, es sintetizada en el hígado y tiene un peso molecular de 65-kDa. Sus principales funciones son: regular la presión oncótica del plasma, actuar como buffer ácido/base y mediar el trasporte de diversos metabolitos, hormonas, vitaminas y medicamentos ${ }^{6}$. La excreción urinaria de albúmina en individuos sanos es menor a $30 \mathrm{mg} /$ día. La albuminuria es moderada o microalbuminuria cuando la excreción urinaria de albúmina oscila entre 30 y $300 \mathrm{mg}$ al día. La proteinuria, macroalbuminuria o albuminuria severa se considera a la excreción urinaria superior a $150 \mathrm{mg} /$ día y proteinuria en rango nefrótico a aquella superior a $3500 \mathrm{mg} / 24 \mathrm{hs}$. El síndrome nefrótico se define como la coexistencia de proteinuria en rango nefrótico y albúmina sérica menor a $3 \mathrm{~g} / \mathrm{dL}^{7}$.

Para detectar proteinuria en orina, se tiene en cuenta distintos métodos como:

1. Tira reactiva: solamente detecta albúmina a partir de $300-500 \mathrm{mg} / 24 \mathrm{hs}$.

2. Sulfosalicílico: detecta todas las proteínas de la orina. Da falsos positivos tras la administración de contrastes yodados.

3. Cuantificación en orina de 24 horas: para microalbuminuria y proteinuria.

4. Cuantificación en orina de 24 horas separada en dos fracciones: de 7 a 23 horas (ortostatismo) y de 23 a 7 horas (reposo nocturno).

5. Cocientes:

- Proteinuria/creatininuria: en muestra simple de orina esporádica: se calcula por el cociente entre proteinuria $(\mathrm{mg} / \mathrm{dL}) /$ creatininuria $(\mathrm{mg} / \mathrm{dL})$. El valor normal es $<0,3$.

- Microalbuminuria/creatininuria: en muestra simple de orina esporádica: se calcula por el cociente entre microalbuminuria $(\mu \mathrm{g} / \mathrm{mL}) /$ creatininuria $(\mathrm{mg} / \mathrm{dL})$. El valor normal es $<30$, hay microalbuminuria si 30-300 y proteinuria $\mathrm{si}>300^{8}$.

La detección y cuantificación adecuada de la proteinuria es de gran importancia en el manejo de pacientes con factores de riesgo de padecer enfermedad renal. La recogida orina de 24 horas resulta engorrosa y no siempre se realiza correctamente. Una forma fácil y fiable es la recolección de orina única para la medición de cociente proteinuria/creatininuria en orina esporádica como herramienta diagnóstica. Asimismo, la simplificación de la obtención y consiguiente realización del cociente en el paciente con proteinuria, podría suponer una disminución del gasto sanitario?. 
Estudios previos sugieren que el cociente proteinuria/creatininuria en una orina al azar refleja con precisión los valores de proteinuria de 24 horas. La recogida de la muestra de orina puede realizarse en cualquier momento del día, aunque se recomienda que sea la primera orina de la mañana. La American Diabetes Association y la National Kidney Foundation recomiendan valorar la presencia de proteinuria (albuminuria severa) o albuminuria moderada (microalbuminuria) para detectar la enfermedad renal crónica. En muchas ocasiones no será necesario recoger orina de 24 horas para cuantificar la excreción de proteínas, siendo suficiente la determinación del cociente ya citado ${ }^{4}$.

La cuantificación de la proteinuria es una prueba de gran valor en la evaluación de las enfermedades renales como un marcador diagnóstico y pronóstico, además de ser esencial en el seguimiento del tratamiento de las glomerulopatías. El patrón de oro es la determinación de la proteinuria en la orina de 24 horas debido a la gran variación en la concentración de la proteína urinaria a lo largo del día por diversos motivos. Vale destacar que la determinación de la proteinuria de 24 horas está asociada a muchas dificultades, como la adherencia del paciente a una colecta adecuada y el proceso de este material en el laboratorio. Por lo tanto en los últimos años, se preconiza la utilización del cociente proteinuria/creatininuria en una muestra de orina al azar como el estudio adecuado para la determinación de proteinuria ya que es simple de realizar, de bajo costo y los valores de repetición se pueden obtener fácilmente ${ }^{10}$. Además, es capaz de predecir la presencia de proteinuria en rango nefrótico con buena sensibilidad y especificidad. Es importante mencionar que las variaciones en el grado de proteinuria de 24 horas a lo largo del tiempo en cada paciente, transcurren de forma paralela a las variaciones en cociente proteinuria/creatininuria, lo que lo hace útil para el control de los posibles tratamientos, aunque no hay acuerdo en todos los estudios. La diferencia entre los dos métodos es menor que la variabilidad en la excreción urinaria de proteínas y la de los propios métodos de medida de la proteinuria, como se puede observar en la tabla $1^{3}$.

Tabla 1

Estudios de correlación de proteinuria de 24 horas con el cociente proteinuria/creatininuria en una muestra aislada de orina. ${ }^{3}$

\begin{tabular}{lcccc}
\hline \multicolumn{1}{c}{ Autores } & Número & Correlación & Sensibilidad & Especificidad \\
\hline Steinhộuslim & 133 & 0,93 & $95-99 \%$ & $97-99 \%$ \\
Torng & 289 & 0,79 & $73-95 \%$ & $33-98 \%$ \\
Rodrigo & 759 & 0,92 & $73-95 \%$ & $96-98 \%$ \\
Zelmanovitz & 167 & 0,72 & $90,5 \%$ & $90,5 \%$ \\
\hline
\end{tabular}

En un estudio realizado en pacientes con enfermedades autoinmunes, en donde compararon las mediciones del cociente proteinuria/creatininuria en muestras de orina esporádica con mediciones de orina de 24 horas en 104 muestras de 90 pacientes que acudían consecutivamente a una unidad de Reumatología, se demostró una correlación altamente significativa $(\mathrm{r}=0,92, \mathrm{p}=<0,001)$. También, una sensibilidad de $100 \% \mathrm{y}$ especificidad de $97 \%{ }^{11}$. Se ha demostrado así que el cociente entre la proteinuria y la creatininuria en una orina esporádica es un método confiable para estimar la proteinuria en orina en gestantes, pacientes trasplantados renales, con nefropatía diabética y en niños ${ }^{12}$. En el Servicio de Nefrología del Hospital del Mar - Barcelona, se realizó un estudio prospectivo observacional con 159 pacientes mayores de 18 años de edad con distintos grados de insuficiencia renal, en donde se obtuvo buena correlación entre la proteinuria de 24 horas y el índice proteinuria/creatininuria en los pacientes que presentaban en orina de 24 horas proteínas entre 300-3499, no observándose correlación en pacientes con proteinuria en rango nefrótico? 
Un valor del cociente proteinuria/creatininuria de 30 a $300 \mathrm{mg} / \mathrm{g}$ ó 0,3 sugiere que la excreción de albúmina es de entre 30 y $300 \mathrm{mg} /$ día y, por lo tanto, el aumento de la albuminuria moderada está probablemente presente $^{13}$. Los valores por encima de $300 \mathrm{mg} /$ día o de 0,3 son indicativos de una mayor severidad de la albuminuria. Este sistema de clasificación requiere que al menos dos de tres muestras caigan dentro del rango de albuminuria moderada, que van aumentando de tres a seis meses ${ }^{13,14}$.

Un ejemplo es un estudio aleatorio que se realizó en 14 sujetos normales, en 13 con diabetes mellitus tipo 1 y en 12 con diabetes mellitus tipo 2, en quienes se tomaron muestras de orina de 24 horas y también una orina al azar para calcular el cociente entre la proteinuria/creatininuria, en donde se observó una estrecha correlación entre las dos mediciones y la variabilidad entre los pacientes era muy pequeña ${ }^{15}$. Una correlación entre la proteinuria/creatininuria por encima de $30 \mathrm{mg} / \mathrm{g}$ o 0,3 tuvo una sensibilidad del 100\% para la detección de un aumento moderado de albuminuria ${ }^{13}$.

Se describen tres advertencias importantes que deben ser consideradas para maximizar la fiabilidad de la orina en el cociente proteinuria/creatininuria:

1. El tiempo óptimo para medir la relación entre la proteinuria/creatininuria en orina espontánea es incierto. Los mejores datos provienen de informes que evaluaron principalmente a los pacientes sin diabetes. En un estudio de 1983, se observó que la mejor correlación con la orina de 24 horas se produjo en muestras obtenidas después de la primera orina de la mañana y antes de acostarse. En contraste, en un estudio posterior y más grande, se encontró la mejor correlación con la primera orina de la mañana, aunque la diferencia en comparación con las muestras de orina en distintos horarios no fue significativa. Generalmente se tiene una ligera preferencia por la primera orina de la mañana, pero si esto es un inconveniente, las muestras pueden ser obtenidas en otro horario durante el día, porque se ha demostrado que las diferencias son mínimas y están dentro del rango de variación fisiológica aceptable. Para las mediciones seriadas, es preferible obtener las muestras aproximadamente a la misma hora del día ${ }^{16}$.

2. El ejercicio vigoroso también es una causa de aumento transitorio en la excreción de albúmina. Por lo tanto, los pacientes deben abstenerse de ejercicio vigoroso en las 24 horas anteriores a la prueba.

3. La precisión de la relación en orina esporádica de la proteinuria/creatininuria se verá disminuida si la excreción de creatinina es sustancialmente diferente del valor esperado; esto es particularmente importante en pacientes con valores límite, por ejemplo, se subestima su valor en los hombres musculosos con una alta tasa de excreción de creatinina y se sobreestima en los pacientes caquécticos en los cuales la masa muscular y la excreción de creatinina se reducen notablemente. La proporción también varía con el género y con la raza / etnicidad en los Estados Unidos, como la excreción de creatinina es significativamente mayor entre los negros no hispanos y los estadounidenses de origen mexicano que entre los blancos no hispanos ${ }^{17}$.

Además, existen otras circunstancias en donde se elevan transitoriamente las proteínas, como el mal control del glucemia en pacientes diabéticos, hipertensión arterial mal controlada, fiebre, cualquier infección, fallo cardiaco, dieta hiperproteica, contaminación por hematuria, la bipedestación, infección urinaria y vaginal. En estas condiciones se debe evitar solicitar el estudio de proteinuria para evitar falsos positivos ${ }^{4}$. La realización de las determinaciones en orina comienza con una adecuada técnica de recolección de la muestras y de su procesamiento inmediato para obtener una óptima información de la prueba. La recolección de la orina debe realizarse en un frasco preferentemente estéril con tapa hermética para impedir su derramamiento y contaminación. La muestra de orina se mantiene estable durante 7 días entre $2-8{ }^{\circ} \mathrm{C}{ }^{18-20}$. En el caso de necesidad de congelar la muestra, se recomienda hacerlo a temperaturas menores o igual a $70^{\circ} \mathrm{C}$. La descongelación se debe realizar a temperatura ambiente y la muestra debe ser homogeneizada con la finalidad de disolver los precipitados que hayan podido formarse. Se aconseja utilizar muestras frescas de orina para la medición 
confiable de albúmina en orina ${ }^{21}$.Si por algún motivo fuese necesario realizar una recolección de 24 horas de la orina, ésta debe mantenerse refrigerada, no siendo necesario añadir ningún conservante en la misma ${ }^{20}$.

\section{Métodos cuantitativos para la medida de proteinuria}

Los métodos más utilizados para la determinación de proteinuria son los turbidimétricos, basados en la floculación fina de las proteínas por acción de compuestos tipo ácido tricloroacético, ácido sulfosalicílico o cloruro de bencetonio y los colorimétricos, basados en la fijación a colorantes (Ponceau-S, azul brillante de Coomassie y Rojo de pirogalol molibdato). Tanto unos como otros presentan diferente sensibilidad y especificidad analítica para los distintos tipos de proteínas, reaccionando en mayor proporción con la albúmina $^{20}$.

No existe actualmente ningún procedimiento de medida definitivo ni material de referencia para la determinación de proteína en orina, lo que da lugar a una gran variabilidad entre los resultados obtenidos en diferentes laboratorios. La mayor variación afecta, sobre todo a las concentraciones bajas y es menos importante para las más elevadas, en parte debido a que estas últimas tienen una mayor concentración relativa de albúmina. Los datos procedentes del Programa de Control Externo de la Calidad de la Sociedad Española de Bioquímica Clínica y Patología Molecular del año 2009 indican que los métodos más empleados para la medida de proteína son los turbidimétricos que utilizan cloruro de bencetonio (48,5\% de los laboratorios) y los de fijación al colorante rojo de pirogalol (44,9\% de los laboratorios) ${ }^{20}$.

\section{Importancia en la valoración de la proteinuria}

Si bien, con la evaluación de la tasa de filtración glomerular, se puede valorar si el paciente padece o no de enfermedad renal, esta información poco o nada habla sobre el pronóstico y la posibilidad de progresión a complicaciones que tiene la enfermedad renal crónica, salvo para pacientes que se encuentran en estadios terminales de enfermedad renal. Para conocer el pronóstico en estadios previos, es necesaria la determinación de albuminuria y/o proteinuria como marcador de daño de estructura renal. La proteinuria se conoce como claro indicador de la velocidad de pérdida de la función renal ya desde la presencia de macroalbuminuria (150 a 300 mg de proteínas en 24 hs), describiéndose así un gran poder predictivo de eventos cardiovasculares tanto coronarios como cerebrovasculares ${ }^{21,22}$.

En los adultos, las causas más frecuentes de nefropatía son la diabetes mellitus y la hipertensión arterial o, en un sentido más amplio, la enfermedad vascular y las glomerulopatías. En la diabetes mellitus la albuminuria es el criterio estándar para evaluar el daño renal relacionado además con el riesgo cardiovascular. La presencia de proteínas en orina en pacientes hipertensos es sobre todo un marcador de daño endotelial difuso y se correlaciona con la morbilidad y la mortalidad cardiovascular. En las enfermedades glomerulares, la albúmina es la principal proteína excretada ${ }^{3}$.

Se reconoce que la proteinuria es un factor de riesgo independiente para la enfermedad cardiovasculary renal, así como un predictor final de daño orgánico, por lo tanto su detección tiene un valor pronóstico y diagnóstico en la identificación y confirmación inicial de la enfermedad renal, así como en la evaluación de la eficacia de la terapéutica y progresión de la enfermedad renal. La Fundación Nacional del Riñón ha recomendado que un aumento de la excreción de proteínas se puede utilizar como una herramienta en pacientes con riesgo de desarrollar enfermedad renal ${ }^{24}$. 


\section{Albuminuria moderada, estrés oxidativo y disfunción endotelial.}

La albuminuria moderada se asocia con una mayor extravasación transcapilar de la albúmina y a un incremento del factor VIII de Von Willebrand, así como de otros marcadores de disfunción endotelial. La presencia de albuminuria moderada puede identificar a una situación de disfunción endotelial generalizada, ya sea cardiovascular y renal, así como un incremento del estrés oxidativo ${ }^{25,26}$. Se ha descripto que la presencia de albuminuria moderada se asocia a la elevación de la Proteína C Reactiva (PCR) y que en sujetos sin diabetes ni afectación renal, las concentraciones de PCR se correlacionan con la reducción evolutiva de la filtración renal, así como la hiperfiltración compensadora, signo precoz de deterioro renal. La reducción de la masa de nefronas funcionantes conlleva a un aumento de la filtración de proteínas plasmáticas, la proteinuria, lo que da lugar a una excesiva reabsorción tubular de proteínas que desencadena, por un lado, hipertrofia de las células tubulares por la producción de factor de crecimiento transformador beta y su definitiva evolución a mioblastos, y por otro, fibrogénesis por expresión de colágeno tipo IV. Esa reabsorción excesiva de proteínas activa la vía del factor nuclear kappa beta y da lugar a la liberación de sustancias vasoactivas y citocinas proinflamatorias, así como factores de crecimiento en el intersticio, reclutamiento de células inflamatorias, proliferación de fibroblastos, fibrosis y deterioro progresivo de la función renal. Incluso en etapas precoces de la disfunción renal, hay signos de respuesta inflamatoria que parece contribuir al progreso de la enfermedad ${ }^{27}$.

$\mathrm{Al}$ interactuar la inflamación, ésta activa múltiples mecanismos proaterogénicos. Así, la grasa visceral especialmente, y también en menor medida el índice de masa corporal (IMC), se relacionan con los marcadores inflamatorios, interleucina 6 (IL-6), PCR y factor de necrosis tumoral alfa (TNF- $\alpha$ ). Valores bajos de adiponectina y adipocina procedente de la grasa visceral se asocian con un aumento de los marcadores inflamatorios plasmáticos, la IL-6 y la PCR. La hiperglucemia aguda aumenta IL-6, el TNF- $\alpha$ y la IL-18, y la hemoglobina glucosilada, correlacionándose estrechamente con los marcadores inflamatorios ${ }^{28}$.

El papel de la inflamación en la hipertensión arterial es el mayor determinante para la progresión de la enfermedad renal. La PCR también se correlaciona con los valores tensionales en hipertensos y con el riesgo de desarrollar hipertensión en normotensos, incluso en pacientes sin otros factores de riesgo cardiovascular ${ }^{29}$.

El principal desencadenante de la respuesta inflamatoria en los pacientes con disfunción renal incipiente es el estrés oxidativo, con la colaboración, o al menos la complicidad, de la PCR al inicio del proceso o la ampliación de su respuesta. La PCR también puede inhibir la expresión de la óxido nítrico sintasa endotelial y neutralizar el óxido nítrico producido por el endotelio sano y la exagerada producción de radicales libres acelera el estrés oxidativo ${ }^{27,30}$. Se describe una estrecha relación entre el estrés oxidativo y el mantenimiento de la hipertensión arterial, alteraciones hemodinámicas a nivel glomerular, lo que conlleva a la persistencia de la proteinuria $^{31}$.

\section{Diabetes mellitus y proteinuria}

Se considera que el aumento de la excreción urinaria de proteínas puede ser una manifestación precoz de la nefropatía diabética ${ }^{13,32}$. Entre las principales manifestaciones clínicas de la nefropatía diabética se citan a la albuminuria, hematuria y con menos frecuencia la enfermedad renal crónica progresiva, cuya evolución puede ser lenta o prevenirse con un tratamiento óptimo. Tanto el aumento de la albuminuria moderada (anteriormente llamada microalbuminuria) como el aumento severo de la albuminuria (anteriormente llamada macroalbuminuria o proteinuria), se consideran un hallazgo que predice un alto riesgo para el futuro de la nefropatía, pudiendo evolucionar a enfermedad renal en etapa terminal en ausencia de tratamiento eficaz ${ }^{33}$. Además se describen anomalías patológicas que se observan en los pacientes con diabetes mellitus de larga data, antes de la aparición de un aumento de la albúmina moderada ${ }^{34}$. Los tres principales cambios histológicos en los glomérulos en la nefropatía diabética según la Clasificación de la Sociedad de Patología Renal son ${ }^{35}$ : 
- Clase I: expansión mesangial o glomeruloesclerosis. No siempre se desarrolla en paralelo, lo que sugiere que puede tener una patogénesis diferente. No hay evidencia de que llegue a involucrar a más del $50 \%$ de los glomérulos. Las membranas basales son mayores a $430 \mathrm{~nm}$ en los hombres y mayor a $395 \mathrm{~nm}$ en las mujeres.

- Clase II: expansión mesangial leve (Clase IIa) o grave (Clase IIb), en ésta última se considera áreas de expansión mayor al $25 \%$ del mesangio total.

- Clase III: la aparición de al menos una lesión de Kimmelstiel-Wilson, es decir, glomeruloesclerosis nodular intracapilar, en un grado menor al 50\% de glomeruloesclerosis focal.

- Clase IV: esclerosis diabética avanzada. Hay más del 50\% de glomeruloesclerosis global atribuible a nefropatía diabética.

Se han realizado estudios en pacientes con y sin nefropatía diabética clínicamente evidente, en quienes se han observado una serie de factores que están asociados con un mayor riesgo de afectación renal. Entre ellos se encuentran ${ }^{36-48}$ :

- La susceptibilidad genética: puede ser un factor determinante de la incidencia y gravedad de la nefropatía diabética. La probabilidad de desarrollar nefropatía diabética se incrementa notablemente en los pacientes con un padre o un hermano que la haya padecido. Estas observaciones se han hecho en pacientes tanto con diabetes mellitus tipo 1 como en la de tipo 2. Un ejemplo es un informe de la diabetes en las familias indígenas Pima, en donde se observó que dos generaciones sucesivas tenían diabetes mellitus tipo 2 y en ellos la probabilidad de que la descendencia pudiera desarrollar proteinuria franca fue 14\% si ninguno de los padres tenía proteinuria, $23 \%$ si uno de los padres tenía proteinuria y $46 \%$ si ambos padres tenían proteinuria ${ }^{38-40}$.

- La edad: el impacto de la edad en el inicio de la diabetes en el riesgo de desarrollar enfermedad renal no está claro.

- La presión arterial: se han realizado estudios prospectivos que han observado una asociación entre las presiones sistémicas superiores y el posterior desarrollo de la nefropatía diabética, ya que produce hipertensión intraglomerular porque evita la vasoconstricción en la arteriola aferente.

La tasa de filtración glomerular: aquellos pacientes con hiperfiltración glomerular parecen estar en mayor riesgo de padecer de enfermedad renal. Esto es cierto para la nefropatía manifiesta si la tasa de filtración glomerular se encuentra por encima de $150 \mathrm{~mL} / \mathrm{min}$, en comparación con un menor grado de hiperfiltración que puede tener un curso más lento, con un menor riesgo de aumento de la albuminuria moderada. El desarrollo de la nefropatía diabética puede estar relacionado con la asociación entre los cambios hemodinámicos.

- La tasa de filtración glomerular: aquellos pacientes con hiperfiltración glomerular parecen estar en mayor riesgo de padecer de enfermedad renal. Esto es cierto para la nefropatía manifiesta si la tasa de filtración glomerular se encuentra por encima de $150 \mathrm{~mL} / \mathrm{min}$, en comparación con un menor grado de hiperfiltración que puede tener un curso más lento, con un menor riesgo de aumento de la albuminuria moderada. El desarrollo de la nefropatía diabética puede estar relacionado con la asociación entre los cambios hemodinámicos como la hipertensión intraglomerular que impulsa la hiperfiltración y los cambios estructurales como hipertrofia glomerular, que aumenta el estrés de la pared con el consecuente aumento del tamaño renal. Por lo cual es imprescindible revertir estos cambios con el control estricto de la glucosa en plasma, la restricción de proteínas en la dieta y la terapia antihipertensiva para retardar la progresión de la enfermedad renal.

- La obesidad: se ha demostrado que los pacientes diabéticos con un alto índice de masa corporal se asocian a un mayor riesgo de padecer de enfermedad renal crónica. Pero no se ha confirmado que la obesidad por sí sola contribuya a la aparición de alguna nefropatía ${ }^{42}$.

- El hábito de fumar: el cigarrillo se asocia a una gran variedad de efectos adversos en pacientes con diabetes. Se evidenció que contribuye a aumento en la albuminuria y el riesgo de enfermedad renal en etapa terminal y por ende una disminución de la supervivencia una vez que comienza el tratamiento sustitutivo renal. Otros efectos del hábito de fumar pueden estar relacionados con un mal control glucémico.

- El uso de anticonceptivos orales: se especula que existe un vínculo entre el uso de anticonceptivos orales y el 
riesgo de nefropatía diabética.

- El control glucémico: la nefropatía diabética es más propensa a desarrollarse en aquellos pacientes con un mal control glucémico.

- Raza: la nefropatía diabética es más frecuente en los pacientes negros que en los caucásicos, debido a los factores socioeconómicos, la dieta, la hipertensión y el mal control de la glucemia.

La nefropatía diabética es un importante marcador de morbimortalidad en el paciente con diabetes. La microalbuminuria y la disminución del filtrado glomerular por debajo de $60 \mathrm{ml} / \mathrm{mil} / 1,73 \mathrm{~m}^{2}$ son considerados como principal factor de riesgo cardiovascular según el informe del Joint National Comitee y de lesión subclínica de órganos diana en las Guías Europeas de las Sociedades Europeas de Hipertensión y Cardiología respectivamente $^{49}$. La presencia de proteinuria en el paciente con diabetes, que incluso presentan cifras normales de filtrado glomerular, es un importante predictor de progresión de enfermedad renal y de mortalidad ${ }^{50}$. También se describe la asociación de la enfermedad renal crónica a un marcado incremento de episodios cardiovasculares como insuficiencia cardiaca, infarto agudo de miocardio, accidente cerebrovascular y arteriopatía periférica, que genéricamente se encuadran en el llamado síndrome cardiorrenal de tipo IV ${ }^{51,52}$.

\section{El efecto de la proteinuria en la hipertensión arterial esencial.}

Los cambios en la función renal que se relacionan con la hipertensión arterial esencial se asocian a una elevada morbilidad y mortalidad cardiovascular. El Framingham Heart Study documentó la relevancia de la proteinuria para el pronóstico cardiovascular en la comunidad. El estudio INSIGHT evaluó el papel de la proteinuria como factor de riesgo en la hipertensión esencial. La presencia de proteinuria al inicio del estudio resultó ser un predictor muy potente para el desarrollo de eventos cardiovasculares y muerte en pacientes con hipertensión arterial esencial y uno o más factores de riesgo cardiovasculares asociados. La función renal debe ser evaluada de forma rutinaria en todos los pacientes hipertensos, y la presencia de alteraciones menores debe ser considerada en la estratificación del riesgo cardiovascular en estos pacientes ${ }^{53,54}$. La microalbuminuria es un marcador de disfunción vascular generalizada y un predictor independiente de riesgo aumentado de morbimortalidad cardiovascular en pacientes con hipertensión arterial y en la población general. Parece haber una relación linear entre la excreción urinaria y el riesgo cardiovascular; a pesar de ello, ahora no está aclarada esa relación, precisándose de más estudios que expliquen esa asociación. El principal determinante de la presencia de microalbuminuria es la sobrecarga tensional. En los hipertensos probablemente es consecuencia de un incremento del filtrado transglomerular de albúmina más que de una menor reabsorción en el túbulo proximal. Esta hiperfiltración puede ser secundaria a factores hemodinámicos o bien a alteraciones estructurales funcionales de la barrera glomerular, como pérdida de las nefronas funcionantes y/o alteraciones de la autorregulación glomerular ${ }^{55}$.

La excreción de albúmina en orina se relaciona con la gravedad de la hipertensión arterial. Se ha observado una relación estadísticamente significativa entre la presión arterial, tanto durante la consulta y especialmente en la medición ambulatoria de la presión arterial (MAPA) con la excreción urinaria de albúmina. También se ha descripto que la presión de pulso, potente predictor de riesgo cardiovascular, sobre todo en ancianos; también se correlaciona estrechamente con la presencia de microalbuminuria o albuminuria moderada ${ }^{57,58}$. En la mayoría de los estudios, la prevalencia de albúmina moderada es más elevada en varones que en mujeres, con un 18,5 y un $12,3 \%$, respectivamente $(p<0,05)$, en la serie de 787 hipertensos del estudio MAGIC y así como en hipertensos de raza negra ${ }^{59}$.

La presencia de microalbuminuria o albuminuria moderada en hipertensos se asocia con un incremento de 2,5 veces del riesgo de complicaciones cardiovasculares como la cardiopatía isquémica, la hipertrofia 
ventricular izquierda, engrosamiento de la pared carotídea, afectación retiniana y enfermedad vascular periférica $^{60-62}$.

\section{La obesidad como factor de riesgo para desarrollar proteinuria.}

Se considera que la obesidad es una causa reconocida de proteinuria y de daño renal progresivo. Estudios recientes muestran que la glomerulopatía asociada a la obesidad es una entidad cada vez más diagnosticada y con una mayor incidencia. También se ha demostrado la participación de la obesidad en la progresión de diferentes patologías renales. La cuantía de la proteinuria es un importante factor de riesgo en la progresión de la enfermedad renal en sujetos con nefropatías diabéticas y no diabéticas, y cualquier medida terapéutica que permita reducir la cantidad de proteinuria desarrollará una influencia favorable, renoprotectora, sobre la evolución a largo plazo de la función renal ${ }^{63}$.

Considerando esto, el papel de la obesidad sobre la evolución de las enfermedades renales es importante, en vista a que la actividad del Sistema Renina Angiotensina Aldosterona (SRAA) está incrementada en la obesidad ${ }^{64,65}$. Estudios recientes sugieren que los pacientes obesos presentan un incremento en la síntesis de aldosterona, lo que podría desempeñar un papel importante en las diferentes complicaciones asociadas a la obesidad, incluyendo el daño renal ${ }^{66,67}$. El bloqueo del SRAA, ya sea con el uso de los inhibidores de la enzima convertidora de angiotensina (IECA) o los antagonistas de los receptores de angiotensina II (ARA II) en monoterapia o en combinación, y más recientemente, con los antagonistas de la renina y aldosterona, representan la medida terapéutica más eficaz en la reducción de la proteinuria en cualquier nefropatía crónica proteinúrica. La renoprotección obtenida por estos fármacos está estrechamente relacionada con su efecto antiproteinúrico $^{68,69}$. Sin embargo, estudios experimentales y clínicos demuestran que la actividad del SRAA está incrementada en la obesidad y que el tejido adiposo, especialmente el visceral, sintetiza todos los componentes del SRAA ${ }^{64,65}$. Por otro lado, los pacientes obesos presentan niveles elevados en plasma de aldosterona y estudios recientes han demostrado que los adipocitos viscerales pueden secretar determinados factores que incrementan la producción de aldosterona por las glándulas suprarrenales, por vías diferentes a las rutas clásicas de la renina-angiotensina. Los ácidos grasos oxidados, comúnmente elevados en obesos, también pueden aumentar la síntesis de aldosterona. Por todo lo mencionado, se podría sugerir un efecto antiproteinúrico más favorable de los antagonistas de aldosterona en los pacientes obesos, debido al hiperaldosteronismo asociado a la obesidad ${ }^{70,71}$, sin quedar atrás los IECA y los ARA II ${ }^{68}$. Cinco estudios controlados muestran que pérdidas de peso logradas por diferentes intervenciones se asocian con descensos de proteinuria medias de hasta 1,7 g. Los análisis de metarregresión muestran que con independencia de los cambios de la presión arterial, cada kilogramo de pérdida de peso en obesos con proteinuria permite estimar un descenso medio de la proteinuria en $110 \mathrm{mg}^{72}$.

\section{Proteinuria glomerular asociada a lupus eritematoso sistémico.}

Más de la mitad de los pacientes con lupus eritematosos sistémico se ven afectados por la nefritis lúpica. Una vez detectada esta afección, aumenta la mortalidad y la morbilidad debido al alto riesgo de padecer de enfermedad renal crónica, con requerimiento de tratamiento hemodialítico en alrededor del $25 \%$ de los pacientes. Se considera a la nefritis lúpica como la primera causa de enfermedad sistémica con afectación renal secundaria ${ }^{73}$.

De acuerdo con las características de cada paciente y la fase de enfermedad en que se encuentran, los parámetros y frecuencia de cuantificación de proteínas en orina debe individualizarse. El patrón de oro es la orina de 24 horas, pero la determinación del cociente de proteinuria/creatininuria en orina esporádica también es útil en la evaluación inicial y en el seguimiento de estos pacientes, si bien, en las fases iniciales se prefiere la orina de 24 horas. En un estudio prospectivo realizado en la Universidad Federal de Sao Paulo se analizaron 72 muestras de orina en pacientes con nefritis lúpica y se constató una buena correlación entre la 
proteinuria de 24 horas y el cociente proteinuria/creatininuria en orina esporádica $(r=0,9)$, no así entre la proteinuria aislada y la proteinuria de 24 horas $^{12}$. Aún no se obtienen datos sobre la utilidad de la albuminuria moderada como marcador de afectación renal crónica en la nefritis lúpica, pero sí tiene valor como predictor de riesgo cardiovascular en estos pacientes. Y también si está presente en combinación con los marcadores serológicos de actividad: anti DNA, C3, C4 y el anti C1-q, más específico para actividad renal.

Se recomienda que los pacientes con nefritis lúpica, proteinuria y/o hipertensión arterial deben recibir fármacos que bloquean el sistema renina-angiotensina-aldosterona (SRAA). También está recomendada la pérdida de peso en los pacientes obesos por su efecto beneficioso sobre la proteinuria y la progresión de enfermedad renal. El estudio prospectivo multicéntrico LUMINA ha concluido que para el tratamiento de pacientes lúpicos que reciben tratamiento con IECA se ve retrasada la nefritis lúpica mediante biopsia renal. La probabilidad de mantenerse libres de afección renal a los 10 años fue del 88,1 \% para quienes recibieron IECA frente al 75,4\% de los que no recibieron $(\mathrm{p}=0,009)$. El grupo tratado con IECA presentó, además, un menor porcentaje de proteinuria y/o nefritis lúpica valorada mediante biopsia renal, que el grupo no tratado $(7,1 \%$ frente al $22,9 \% ; p=0,01)^{73}$.

\section{Objetivos}

- Determinar la correlación entre los valores del cociente de proteinuria/creatininuria en una orina al azar y la proteinuria de 24 horas.

- Estimar la sensibilidad, especificidad, valor predictivo positivo y valor predictivo negativo del cociente proteinuria/creatininuria en una orina al azar en relación a la proteinuria de 24 horas.

\section{Materiales y métodos}

Diseño: estudio descriptivo, observacional, prospectivo, de corte transverso, con componente analítico

Población de estudio: varones y mujeres, mayores de edad, con factores de riesgo de enfermedad renal crónica, que hayan consultado en el Hospital Nacional (Itauguá) en el consultorio de Clínica Médica y Hospital día de mayo a noviembre del año 2014.

Criterios de inclusión: portadores de hipertensión arterial, diabetes mellitus, enfermedades autoinmunes y pacientes sanos con antecedentes patológicos familiares de enfermedad renal crónica.

Criterios de exclusión: pacientes con infección de vías urinarias u otras infecciones, malformación de las vías urinarias, hematuria, diabetes mellitus descompensada, insuficiencia cardiaca descompensada, pacientes con sonda vesical, internados en unidad de cuidados intensivos, portadores de enfermedad renal crónica, errores en la toma y procesamiento de las muestras, pacientes que no accedieron a ingresar al estudio y resultados de laboratorio que no fueron procesados en el Hospital Nacional de Itauguá.

Muestreo: no probabilístico de casos consecutivos.

Reclutamiento: los sujetos con los criterios de inclusión eran invitados a participar del estudio. Si aceptaban participar se les solicitaban muestras de orina. Los médicos de consultorio participaron en el reclutamiento.

Procedimiento de medición: se recolectó orina de 24 horas y una muestra de orina al azar. Las muestras en el laboratorio del Hospital Nacional (Itauguá).

Variables: edad, sexo, tiempo de enfermedad, factores de riesgo para enfermedad renal crónica, creatininuria al azar, proteinuria al azar, cociente proteinuria/creatininuria en una orina al azar, proteinuria de $24 \mathrm{hs}$. 
Instrumentos de medición: se utilizó el reactivo $M-T P$ para medir la concentración de proteínas por un tiempo de punto final a tiempo fijo, junto con el calibrador SYNCHRON ${ }^{\circledR}$ systems, calibrador para microproteínas y determinación cuantitativa de creatinina en orina y el sistema SYNCHRON CX ${ }^{\circledR}$ para la determinación cuantitativa de proteína total en orina.

Gestión de datos: las variables fueron registradas en una planilla electrónica y sometidas a estadística descriptiva con Epi Info $7^{\circledR}$. El coeficiente de correlación se calculó con Microsoft Excel $2013^{\circledR}$. La sensibilidad, especificidad, VPP, VPN y sus intervalos de confianza se calcularon con Epi Dat $3.1^{\circledR}$.

\section{Hipótesis:}

$\mathbf{H}_{0}$ : no existe correlación estadísticamente significativa entre el cociente de proteinuria/creatininuria en una orina al azary la proteinuria de $24 \mathrm{hs}$.

$\mathbf{H}_{\mathbf{a}}$ : existe correlación estadísticamente significativa entre el cociente de proteinuria/creatininuria en una orina al azary la proteinuria de $24 \mathrm{hs}$.

Estimación del tamaño de muestra: se esperó una correlación $r=0,9^{3}$. Con el programa estadístico Epi Dat $3.1^{\circledR}$ se calculó que, para un error alfa 1\%, error beta 1\%, el tamaño mínimo a incluir debía ser 13 sujetos.

\section{Resultados}

En los 60 pacientes estudiados predominó el sexo femenino: 43 casos $(71,67 \%)$. La media de la edad fue $46 \pm 17$ años. la patología más frecuente fue la hipertensión arterial (tabla 2).

Tabla 2

Patologías de los pacientes evaluados (n 60)

\begin{tabular}{lc}
\hline \multicolumn{1}{c}{ Patologías } & Frecuencia \\
\hline Hipertensión arterial & 19 \\
Lupus eritematoso sistemático & 10 \\
Hipertensión arterial y lupus eritematoso sistemático & 9 \\
Hipertensión arterial y diabetes mellitus & 8 \\
Hipertensión arterial y obesidad & 6 \\
Diabetes mellitus & 5 \\
Artritis reumatoide & 1 \\
Nefritis por IgA & 1 \\
Hipertensión arterial y artritis reumatoide & 1 \\
\hline
\end{tabular}

La media de la proteinuria al azar fue 45,82 $\pm 95,31 \mathrm{~g} / \mathrm{dL}$. La media de la creatininuria al azar fue $122 \pm$ 93,42 g/dL. La media del cociente proteinuria/creatininuria en orina al azar fue 0,49 $\pm 1,04$. La media de la proteinuria de 24 horas fue $560,75 \pm 1612,40 \mathrm{mg} / 24 \mathrm{hs}$. 
El coeficiente de correlación Pearson entre la proteinuria de 24 horas y el cociente proteinuria/creatininuria de toda la muestra fue 0,9 (gráfico 1 ).

\section{Gráfico 1}

Correlación entre proteinuria de 24 horas y el cociente proteinuria/creatininuria (n= 60).

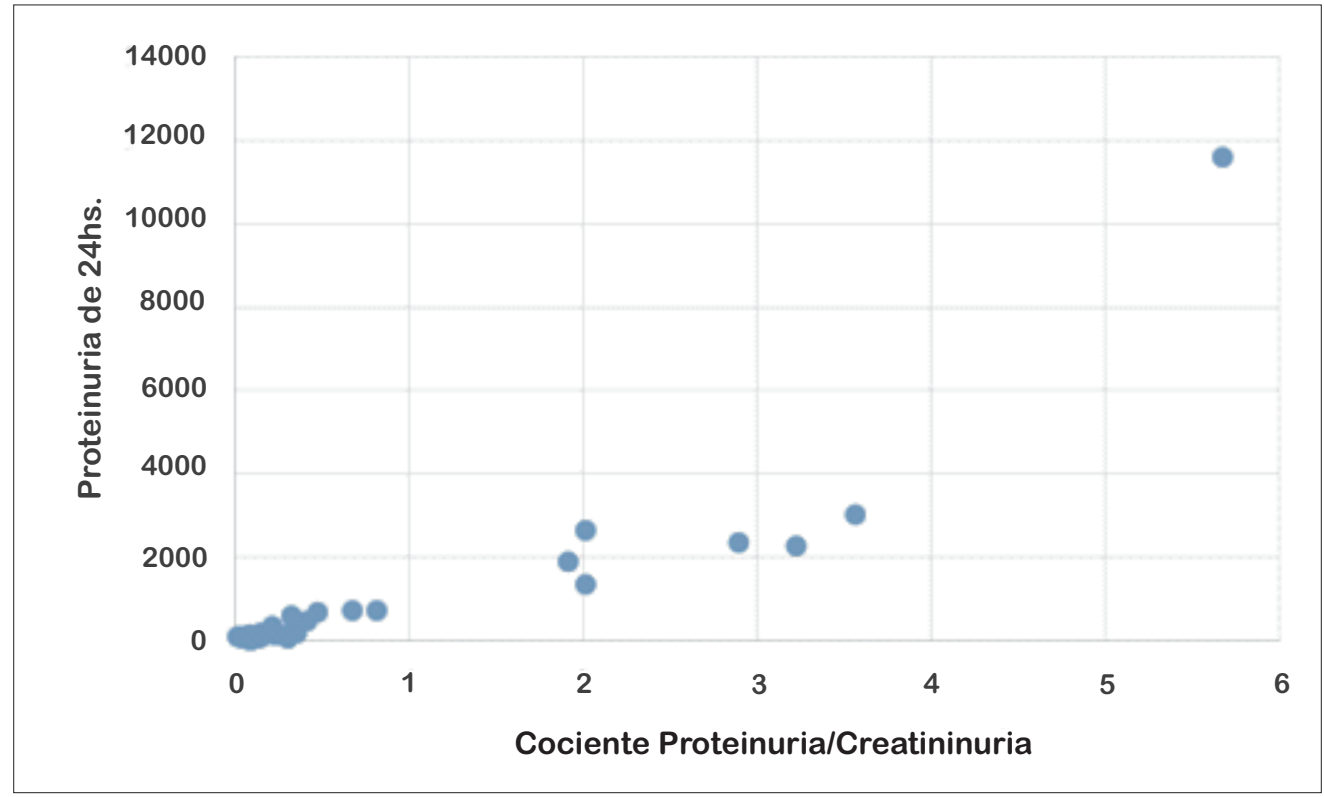

Posteriormente se hicieron nuevos cálculos, incluyendo sólo a los sujetos con proteinuria de 24 hs entre 150 y 2999 mg y a aquellos con cociente proteinuria/creatininuria >0,3. La correlación fue 0,9 (gráfico 2).

\section{Gráfico 2}

\section{Correlación entre la proteinuria de 24 horas de rango entre $150-2999 \mathrm{mg} /$ día y el cociente proteinuria/creatininuria $>0,3$ (n 16)}

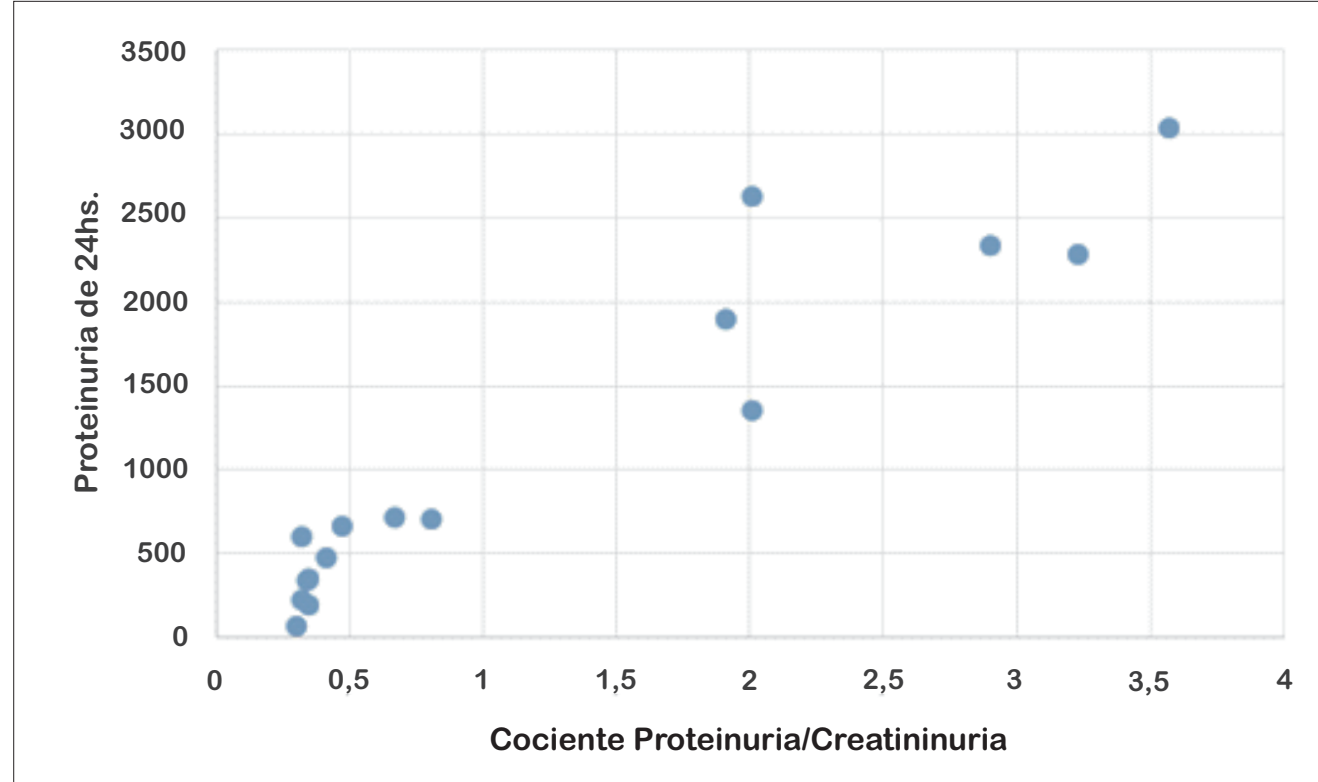

Pero al correlacionar a los sujetos con proteinuria de 24 horas $<150 \mathrm{mg}$ y cociente de proteinuria/creatininuria de $<0,3$, el valor obtenido fue 0,7 (gráfico 3). 


\section{Gráfico 3}

\section{Correlación entre la proteinuria de 24 horas $<150 \mathrm{mg} /$ día y el cociente proteinuria/creatininuria $<0,3(n=43)$.}

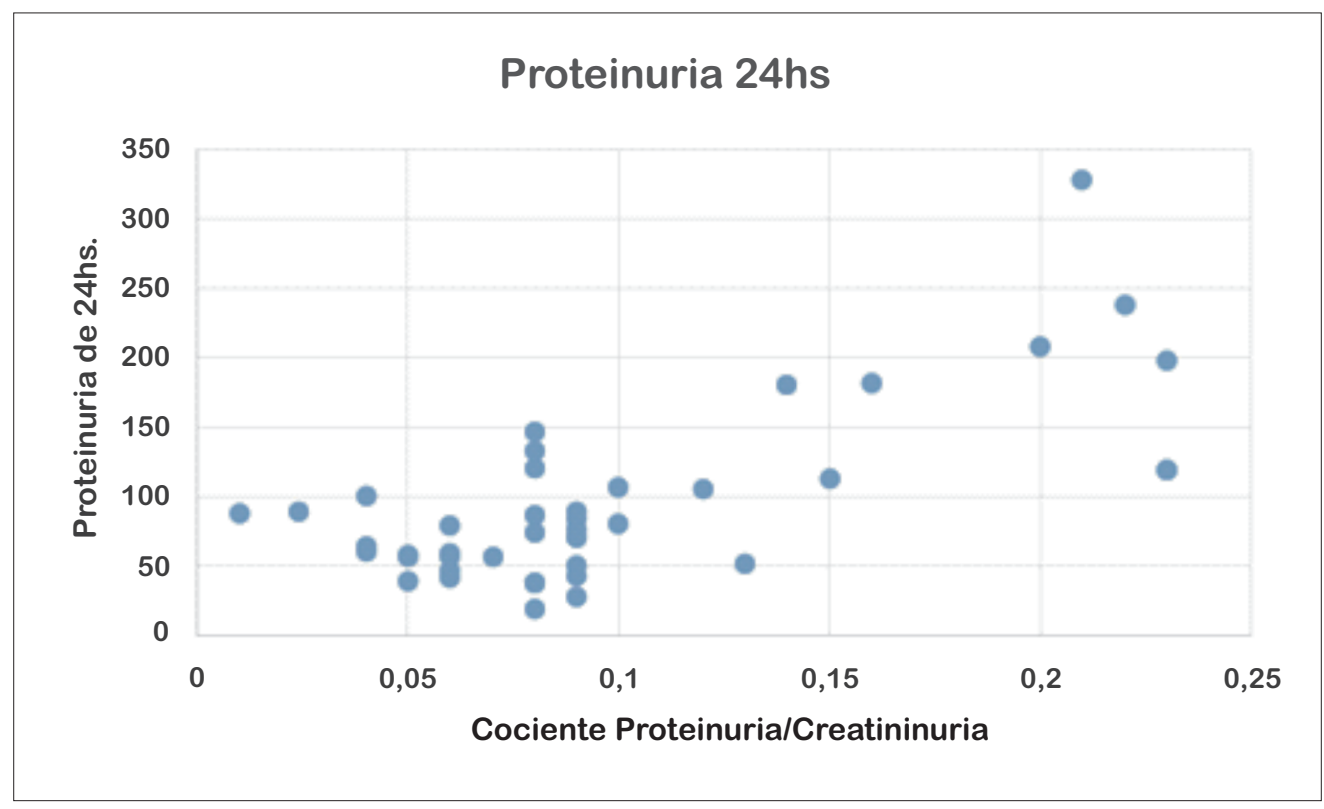

El cociente proteinuria/creatininuria tuvo una sensibilidad para detectar proteinuria de 94,1\% (IC95\% 79-100), especificidad de 100\% (IC95\% 98-100), valor predictivo positivo 100\% (IC95\% 96-100) y valor predictivo negativo $97,7 \%$ (IC95\% 92-100).

\section{Discusión}

La cuantificación adecuada de proteinuria de 24 horas es una tarea engorrosa, que no siempre se realiza correctamente, además que resulta difícil su adherencia en pacientes con alteración del estado de conciencia, retraso mental y en ancianos. La cuantificación por medio del cociente proteinuria/creatininuria es una estrategia de gran valor, por su técnica simple y fácil de colectar. Si bien no es el gold estándar en cuanto a detección de proteinuria, en este estudio se ha observado una significativa correlación con la proteinuria de 24 horas, coincidente con otras investigaciones ${ }^{32,43}$.

La mayor cantidad de los pacientes $(n=46)$ presentó proteinuria $<150 \mathrm{mg} / 24$ hs o un cociente proteinuria/creatininuria $<0,3$, quizá porque se incluyeron a pacientes compensados en el contexto de su patología. En el caso de los hipertensos $(71,67 \%)$, se podría justificar que este grupo de pacientes presentó menos proteinuria debido a los efectos del tratamiento antihipertensivo demostrado en muchas investigaciones ${ }^{52,68,69,73}$. La hipertensión arterial es el principal gatillo para el inicio de la proteinuria debido a la sobrecarga tensional y a un incremento del filtrado transglomerular por la falta de vasoconstricción de la arteriola aferente, produciéndose así la hiperfiltración de la albúmina ${ }^{55}$. Entre las comorbilidades asociadas a la hipertensión arterial se advirtió que la diabetes mellitus ocupa el primer lugar (19,05\%) coincidiendo con la literatura en donde se ha asociado a la nefropatía diabética con la persistencia de presiones sistémicas elevadas $^{41}$.

También se pudo apreciar que la hipertensión arterial cursa con la obesidad como comorbilidad en $14,29 \%$ de los casos, siendo ésta una causa reconocida de proteinuria y de daño renal progresivo, ya que la actividad del sistema renina angiotensina aldosterona se encuentra incrementada en la obesidad ${ }^{63-65}$. 
El lupus eritematoso sistémico fue una patología frecuente encontrada en la consulta $(\mathrm{n}=19)$. Se considera a la proteinuria en la nefritis lúpica como predictor de riesgo cardiovascular ${ }^{73}$. Posiblemente esta cantidad de pacientes también haya influido en los niveles relativamente normales de proteinuria por no encontrarse los mismos en la fase activa de la enfermedad.

Este estudio demostró que existe una correlación casi perfecta $(\mathrm{r}=0,9)$ y estadísticamente significativa $(p<0,001)$ entre la proteinuria de 24 horas y el cociente proteinuria/creatininuria en orina al azar para valores de proteinuria entre 150-3000 mg en 24 horas ó $\geq 0,3$ para el cociente proteinuria/creatininuria, pero no fue así para pacientes que presentaban valores inferiores $(r=0,7)$. Este fenómeno se debe a que el cociente proteinuria/creatininuria no es muy eficaz para detectar proteínas cuando los valores en orina de 24 horas son entre 30-150 mg/24 horas. En este caso es conveniente realizar el cociente microalbininuria/creatininuria ${ }^{8}$.

Diversos estudios observacionales transversales avalan la correlación entre ambas mediciones, destacando su confiabilidad y bajo costo para el paciente. En un estudio publicado recientemente en el Servicio de Nefrología del Hospital del Mar de Barcelona, se demostró que no existe esta correlación en proteinuria en rango nefrótico, por lo cual, de los 60 pacientes, se excluyó al sujeto con proteinuria en ese rango ${ }^{9}$. Sería interesante realizar un nuevo estudio en donde se incluyeran a pacientes con proteinuria en rango nefrótico en una cantidad considerable y evaluar la correlación en esa muestra. Tampoco estaría demás apreciar qué importancia tiene la búsqueda de la correlación entre microalbuminuria/creatininuria al azar y proteinuria de 24 hs y qué tanto es factible, ya que solo detecta albuminuria entre 30 y $300 \mathrm{mg}^{7}$. El actual estudio aportó un resultado estadísticamente significativo en pacientes a partir de una proteinuria de $150 \mathrm{mg} / 24 \mathrm{hs}$, lo que correspondería ya a la presencia de albuminuria moderada.

Como prueba diagnóstica, la comparación entre el índice de proteinuria/creatininuria vs. la proteinuria de 24 hs mostró gran sensibilidad (94,1\%), especificidad (100\%), valor predictivo positivo (100\%) y valor predictivo negativo $(97,7 \%)$, valores que coinciden con el estudio realizado por Steinhồuslin $\mathrm{F} \mathrm{et} \mathrm{al}^{74}$.

Se aconseja que en pacientes con factores de riesgo se realicen estos dos estudios en paralelo luego de la primera consulta, para obtener un valor basal y durante el seguimiento puede ser útil solamente el cociente proteinuria/creatininuria en orina al azar. La prueba debe repetirse dos veces más durante un periodo de tres a seis meses para confirmar que la excreción de albúmina es elevada persistentemente ${ }^{32,43}$. Pero es importante resaltar que un método no sustituye al otro. Un ejemplo es el caso de la nefritis lúpica, en la cual es de importancia la cuantificación de proteinuria de 24 horas durante su periodo de actividad por la posibilidad de que el paciente presente proteinuria en rango nefrótico ${ }^{12}$.

La debilidad de este trabajo fue la cantidad de pacientes incluidos en el estudio (pero sí dentro de la suma de muestras necesarias para que éste sea significativo). Varios pacientes no ingresaron al estudio, en vista a que se deseaba descartar a los que podrían presentar falsos positivos como por ejemplo, el caso de la proteinuria por infección o por ejercicio extremo, portadores de sonda vesical, a los que presentaban descompensación de su patología de base y enfermedad renal crónica establecida, con el fin de realizar así un cribado en los pacientes que se encuentran en peligro de presentar algún factor de riesgo cardiovascular y de padecer de enfermedad renal crónica.

En conclusión, existe una correlación casi perfecta $(r=0,9)$ entre los valores del cociente de proteinuria/creatininuria en una orina al azar y la proteinuria de 24 horas. El cociente proteinuria/creatininuria permite detectar proteinuria con una sensibilidad 94,1\% (IC 79\%-100), especificidad 100\% (IC 98\%-100\%), valor predictivo positivo 100\% (IC95\% 96-100) y valor predictivo negativo $97,7 \%$ (IC95\% 92-100). 


\section{Referencias bibliográficas}

1. Coresh J, Selvin E, Stevens LA, Manzi J, Kusek JW, Eggers P, Van Lente F, Levey AS. Prevalence of chronic kidney disease in the United States. JAMA. 2007 Nov 7; 298(17):2038-47.

2. Alegre JR, Alles A, Angerosa M, Bianchi ME, Dorado E, Etchegoyen MC, et al. Documento de Consenso: Implicancia de la proteinuria en el diagnóstico y seguimiento de la enfermedad renal crónica. Acta Bioquím Clín Latinoam. 2013; 47 (3): 613-25.

3. Rodrigo Calabia E. Medida de la función renal. Evaluación del cociente microalbuminuria/creatinina. Valor de la tira reactiva y del examen del sedimento urinario. Indicaciones para solicitar ecografía renal. Nefrologia. 2004; 24 Supl.(6): 35-46.

4. Regeniter A, Freidank H, Dickenmann M, Boesken WH, Siede WH. Evaluation of proteinuria and GFR to diagnose and classify kidney disease: systematic review and proof of concept. Eur J Intern Med. 2009 Oct; 20(6):556-61.

5. Kashif W, Siddiqi N, Dincer AP, Dincer HE, Hirsch S. Proteinuria: how to evaluate an important finding. Cleve Clin J Med. 2003 Jun;70(6):535-7.

6. Xue L, Lou Y, Feng X, Wang C, Ran Z, Zhang X. Prevalence of chronic kidney disease and associated factors among the Chinese population in Taian, China. BMC Nephrol. 2014 Dec 21; 15(1): 205.

7. Brandt JR, Jacobs A, Raissy HH, Kelly FM, Staples AO, Kaufman E, Wong CS. Orthostatic proteinuria and the spectrum of diurnal variability of urinary protein excretion in healthy children. Pediatr Nephrol. 2010 Jun; 25(6): 1131-7.

8. Birck R, Krzossok S, Markowetz F, Schnülle P, van der Woude FJ, Braun C. Acetylcysteine for prevention of contrast nephropathy: meta-analysis. Lancet. 2003 Aug 23; 362(9384): 598-603.

9. Montero N, Soler MJ, Pascual MJ, Barrios C, Márquez E, Rodríguez E, et al. Correlación entre el cociente proteína/creatinina en orina esporádica y las proteínas en orina de 24 horas. Nefrologia. 2012; 32(4): 494501.

10. Matar HE, Peterson P, Sangle S, D'Cruz DP. Correlation of 24-hour urinary protein quantification with spot urine protein:creatinine ratio in lupus nephritis. Lupus. 2012 Jul;21(8):836-9.

11. Ralston SH, Caine N, Richards I, O'Reilly D, Sturrock RD, Capell HA. Screening for proteinuria in a rheumatology clinic: comparison of dipstick testing, 24 hour urine quantitative protein, and protein/creatinine ratio in random urine samples. Ann Rheum Dis. 1988 Sep; 47(9): 759-63.

12. Solorzano GTM, Silva MV, Moreira SR, Nishida SK, Kirsztajn GM. Urinary protein/creatinine ratio versus 24hour proteinuria in the evaluation of lupus nephritis. J Bras Nefrol. 2012; 34(1): 64-7.

13. Ali A, Taj A, Amin MJ, Iqbal F, Iqbal Z. Correlation between microalbuminuria and hypertension in type 2 diabetic patients. Pak J Med Sci. 2014 May; 30(3): 511-4.

14. Levey AS, Eckardt KU, Tsukamoto Y, Levin A, Coresh J, Rossert J, De Zeeuw D, Hostetter TH, Lameire N, Eknoyan G. Definition and classification of chronic kidney disease: a position statement from Kidney Disease: Improving Global Outcomes (KDIGO). Kidney Int. 2005 Jun; 67(6): 2089-100.

15. Gyamlani GG, Bergstralh EJ, Slezak JM, Larson TS. Urinary albumin to osmolality ratio predicts 24-hour urine albumin excretion in diabetes mellitus. Am J Kidney Dis. 2003 Oct; 42(4): 685-92.

16. Witte EC, Lambers Heerspink HJ, de Zeeuw D, Bakker SJ, de Jong PE, Gansevoort R. First morning voids are more reliable than spot urine samples to assess microalbuminuria. J Am Soc Nephrol. 2009 Feb; 20(2): 43643.

17. Younes N, Cleary PA, Steffes MW, de Boer IH, Molitch ME, Rutledge BN, et al. Comparison of urinary albumincreatinine ratio and albumin excretion rate in the diabetes control and complications trial/epidemiology of diabetes interventions and complications study. Clin J Am Soc Nephrol. 2010 Jul; 5(7): 1235-42.

18. Halimi JM, Hadjadj S, Aboyans V, Allaert FA, Artigou JY, Beaufils M, et al. Microalbuminuria and urinary albumin excretion: French clinical practice guidelines. Diabetes Metab. 2007 Sep; 33(4): 303-9.

19. Gansevoort RT, Brinkman J, Bakker SJ, De Jong PE, de Zeeuw D. Evaluation of measures of urinary albumin excretion. Am J Epidemiol. 2006 Oct 15; 164(8): 725-7.

20. Wu HY, Peng YS, Chiang CK, Huang JW, Hung KY, Wu KD, Tu YK, Chien KL. Diagnostic performance of random urine samples using albumin concentration vs ratio of albumin to creatinine for microalbuminuria screening in patients with diabetes mellitus: a systematic review and meta-analysis. JAMA Intern Med. 2014 Jul; 174(7): 1108-15. 
21. Brinkman JW, de Zeeuw D, Lambers Heerspink HJ, Gansevoort RT, Kema IP, de Jong PE, Bakker SJ. Apparent loss of urinary albumin during long-term frozen storage: HPLC vs immunonephelometry. Clin Chem. 2007 Aug; 53(8): 1520-6.

22. de Jong PE, Curhan GC. Screening, monitoring, and treatment of albuminuria: Public health perspectives. J Am Soc Nephrol. 2006 Aug; 17(8): 2120-6.

23. Remuzzi G, Ruggenenti P, Benigni A. Understanding the nature of renal disease progression. Kidney Int. 1997 Jan; 51(1): 2-15.

24. Bailie GR, Uhlig K, Levey AS. Clinical practice guidelines in nephrology: Evaluation, classification, and stratification of chronic kidney disease. Pharmacotherapy. 2005 Apr; 25(4): 491-502.

25. Yuyun MF, Adler AI, Wareham NJ. What is the evidence that microalbuminuria is a predictor of cardiovascular disease events ${ }^{\circ}$ Curr Opin Nephrol Hypertens. 2005 May; 14(3): 271-6.

26. Vidt DG. Inflammation in renal disease. Am J Cardiol. 2006 Jan 16; 97(2A): 20A-27A.

27. Guérin AP, Pannier B, Marchais SJ, London GM. Cardiovascular disease in the dialysis population: prognostic significance of arterial disorders. Curr Opin Nephrol Hypertens. 2006 Mar; 15(2): 105-10.

28. Stuveling EM, Hillege HL, Bakker SJ, Gans RO, De Jong PE, De Zeeuw D. Creactive protein is associated with renal function abnormalities in a non-diabetic population. Kidney Int. 2003 Feb; 63(2): 654-61.

29. Amann K, Gross ML, Ritz E. Pathophysiology underlying accelerated atherogenesis in renal disease: closing in on the target. J Am Soc Nephrol. 2004 Jun; 15(6): 1664-6.

30. Currie G, McKay G, Delles C. Biomarkers in diabetic nephropathy: Present and future. World J Diabetes. 2014 Dec 15; 5(6): 763-76.

31. Dell'omo G, Giorgi D, Di Bello V, Mariani M, Pedrinelli R. Blood pressure independent association of microalbuminuria and left ventricular hypertrophy in hypertensive men. J Intern Med. 2003 Jul; 254(1): 76-84.

32. Sacks DB, Arnold M, Bakris GL, Bruns DE, Horvath AR, Kirkman MS, et al. Guidelines and recommendations for laboratory analysis in the diagnosis and management of diabetes mellitus. Diabetes Care. 2011 Jun; 34(6): e61-99.

33. de Boer IH, Rue TC, Cleary PA, Lachin JM, Molitch ME, Steffes MW, et al. Long-term renal outcomes of patients with type 1 diabetes mellitus and microalbuminuria: an analysis of the diabetes control and complications trial/epidemiology of diabetes interventions and complications cohort. Arch Intern Med. 2011 Mar 14; 171(5): 412-20.

34. Adler S. Diabetic nephropathy: Linking histology, cell biology, and genetics. Kidney Int. 2004 Nov; 66(5): 2095-106.

35. Tervaert TW1, Mooyaart AL, Amann K, Cohen AH, Cook HT, Drachenberg CB, et al. Pathologic classification of diabetic nephropathy. J Am Soc Nephrol. 2010 Apr; 21(4): 556-63.

36. Tapp RJ, Shaw JE, Zimmet PZ, Balkau B, Chadban SJ, Tonkin AM, Welborn TA, Atkins RC. Albuminuria is evident in the early stages of diabetes onset: results from the Australian Diabetes, Obesity, and Lifestyle Study (AusDiab). Am J Kidney Dis. 2004 Nov; 44(5): 792-8.

37. Macisaac RJ, Ekinci EI, Jerums G. Markers of and risk factors for the development and progression of diabetic kidney disease. Am J Kidney Dis. 2014 Feb; 63(2 Suppl 2): S39-62.

38. Trevisan R, Viberti G. Genetic factors in the development of diabetic nephropathy. J Lab Clin Med. 1995 Oct; 126(4):342-9.

39. Pettitt DJ, Saad MF, Bennett PH, Nelson RG, Knowler WC. Familial predisposition to renal disease in two generations of Pima Indians with type 2 (non-insulin-dependent) diabetes mellitus. Diabetologia. 1990 Jul; 33(7): 438-43.

40. Satko SG, Langefeld CD, Daeihagh P, Bowden DW, Rich SS, Freedman BI. Nephropathy in siblings of African Americans with overt type 2 diabetic nephropathy. Am J Kidney Dis. 2002 Sep; 40(3): 489-94.

41. Bakris GL. Recognition, pathogenesis, and treatment of different stages of nephropathy in patients with type 2 diabetes mellitus. Mayo Clin Proc. 2011 May; 86(5): 444-56.

42. de Boer IH, Sibley SD, Kestenbaum B, Sampson JN, Young B, Cleary PA, et al. Central obesity, incident microalbuminuria, and change in creatinine clearance in the epidemiology of diabetes interventions and complications study. J Am Soc Nephrol. 2007 Jan; 18(1): 235-43.

43. Gross JL, de Azevedo MJ, Silveiro SP, Canani LH, Caramori ML, Zelmanovitz T. Diabetic nephropathy: diagnosis, prevention, and treatment. Diabetes Care. 2005 Jan; 28(1): 164-76. 
44. Rosas Guzmán J, García Rubí E, Gómez Pérez FJ, Calles J, Barceló A, García G, et al. Prevención, diagnóstico y tratamiento temprano de la Nefropatía Diabética. Revista de ALAD /Internet/. 2009 /citado 1 dic. 2014./; 17(3): 106-114. Disponible en: http://www.revistaalad.com/website/articulo. $\operatorname{asp}^{\circ} \mathrm{id}=98$.

45. Eknoyan G, Hostetter T, Bakris GL, Hebert L, Levey AS, Parving HH, Steffes MW, Toto R. Proteinuria and other markers of chronic kidney disease: a position statement of the national kidney foundation (NKF) and the national institute of diabetes and digestive and kidney diseases (NIDDK). Am J Kidney Dis. 2003 Oct; 42(4): 617-22.

46. Newman DJ, Mattock MB, Dawnay AB, Kerry S, McGuire A, Yaqoob M, Hitman GA, Hawke C. Systematic review on urine albumin testing for early detection of diabetic complications. Health Technol Assess. 2005 Aug; 9(30): iii-vi, xiii-163.

47. Mattix HJ, Hsu CY, Shaykevich S, Curhan G. Use of the albumin/creatinine ratio to detect microalbuminuria: implications of sex and race. J Am Soc Nephrol. 2002 Apr; 13(4): 1034-9.

48. ADVANCE Collaborative Group, Patel A, MacMahon S, Chalmers J, Neal B, Billot L, Woodward M, et al. Intensive blood glucose control and vascular outcomes in patients with type 2 diabetes. N Engl J Med. 2008 Jun 12;358(24): 2560-72.

49. Gómez-Huelgas R, Martínez-Castelao A, Artola S, Górriz JL, Menéndez E. Consensus document on treatment of type 2 diabetes in patients with chronic kidney disease. Nefrología. 2014; 34(1): 34-45.

50. Adler AI, Stevens RJ, Manley SE, Bilous RW, Cull CA, Holman RR. Development and progression of nephropathy in type 2 diabetes: The United Kingdom Prospective Diabetes Study (UKPDS 64). Kidney Int. 2003 Jan; 63(1): 225-32.

51. House AA, Ronco C. The burden of cardiovascular risk in chronic kidney disease and dialysis patients: cardiorenal syndrome type 4. Contrib Nephrol. 2011; 171:50-6.

52. Gaede P, Tarnow L, Vedel P, Parving HH, Pedersen O. Remission to normoalbuminuria during multifactorial treatment preserves kidney function in patients with type 2 diabetes and microalbuminuria. Nephrol Dial Transplant. 2004 Nov; 19(11): 2784-8.

53. Segura J, Campo C, Ruilope LM. Effect of proteinuria and glomerular filtration rate on cardiovascular risk in essential hypertension. Kidney Int Suppl. 2004 Nov; (92): S45-9.

54. Stakhova TIu, Shcherbak AV, Kozlovskaia LV, Taranova MV, Balkarov IM. Clinical value of the determination of markers for endothelial dysfunction endothelin-1, microalbuminuria and tubulointerstitial tissue lesion $\beta 2$-microglobulin, monocyte chemotactic protein-1 in hypertensive patients with uric acid metabolic disorders. Ter Arkh. 2014; 86(6): 45-51.

55. González Maqueda I. La microalbuminuria como factor pronóstico en el enfermo cardiovascular. Rev Esp Cardiol Supl. 2007; 7(Supl.A): 31-43.

56. Cirillo M, Stellato D, Laurenzi M, Panarelli W, Zanchetti A, De Santo NG. Pulse pressure and isolated systolic hypertension: Association with microalbuminuria. Kidney Int. 2000 Sep; 58(3): 1211-8.

57. Schrier RW, Estacio RO, Esler A, Mehler P. Effects of aggressive blood pressure control in normotensive type 2 diabetic patients on albuminuria, retinopathy and strokes. Kidney Int. 2002 Mar; 61(3): 1086-97.

58. Lurbe E, Redon J, Kesani A, Pascual JM, Tacons J, Alvarez V, Batlle D. Increase in nocturnal blood pressure and progression to microalbuminuria in type 1 diabetes. N Engl J Med. 2002 Sep 12; 347(11): 797-805.

59. Pontremoli R, Sofia A, Ravera M, Nicolella C, Viazzi F, Tirotta A, et al. Prevalence and clinical correlates of microalbuminuria in essential hypertension: the MAGIC Study. Microalbuminuria: A Genoa Investigation on Complications. Hypertension. 1997 Nov; 30(5): 1135-43.

60. Tuttle KR. Cardiovascular implications of albuminuria. J Clin Hypertens (Greenwich). 2004 Nov; 6(11 Suppl 3): 13-7.

61. Jager A, Kostense PJ, Ruhé HG, Heine RJ, Nijpels G, Dekker JM, Bouter LM, Stehouwer CD. Microalbuminuria and peripheral arterial disease are independent predictors of cardiovascular and all-cause mortality, especially among hypertensive subjects: Five-year follow-up of the hoorn study. Arterioscler Thromb Vasc Biol. 1999 Mar; 19(3): 617-24.

62. Jensen JS, Feldt-Rasmussen B, Strandgaard S, Schroll M, Borch-Johnsen K. Arterial hypertension, microalbuminuria, and risk of ischemic heart disease. Hypertension. 2000 Apr; 35(4): 898-903.

63. Morales E, Huerta A, Gutiérrez E, Gutiérrez Solís E, Segura J, Praga M. The antiproteinuric effect of the blockage of the renin-angiotensin-aldosterone system (RAAS) in obese patients. Which treatment option is the most effective ${ }^{\circ}$ Nefrologia. 2009; 29(5): 421-9. 
64. Xu ZG, Lanting L, Vaziri ND, Li Z, Sepassi L, Rodriguez-Iturbe B, Natarajan R. Upregulation of angiotensin II type 1 receptor, inflammatory mediators, and enzymes of arachidonate metabolism in obese Zucker rat kidney: reversal by angiotensin II type 1 receptor blockade. Circulation. 2005 Apr 19; 111(15): 1962-9.

65. Engeli S, Böhnke J, Gorzelniak K, Janke J, Schling P, Bader M, Luft FC, Sharma AM. Weight loss and the reninangiotensin-aldosterone system. Hypertension. 2005 Mar; 45(3): 356-62.

66. Krug AW, Ehrhart-Bornstein M. Aldosterone and metabolic syndrome: Is increased aldosterone in metabolic syndrome patients an additional risk factor ${ }^{\circ}$ Hypertension. 2008 May; 51(5): 1252-8.

67. Nagase M, Yoshida S, Shibata S, Nagase T, Gotoda T, Ando K, Fujita T. Enhanced aldosterone signaling in the early nephropathy of rats with metabolic syndrome: possible contribution of fat-derived factors. J Am Soc Nephrol. 2006 Dec; 17(12):3438-46.

68. Parving HH, Persson F, Lewis JB, Lewis EJ, Hollenberg NK. Aliskiren combined with losartan in type 2 diabetes and nephropathy. N Engl J Med. 2008 Jun 5; 358(23): 2433-46.

69. Jafar TH, Schmid CH, Landa M, Giatras I, Toto R, Remuzzi G, et al. Angiotensin-converting enzyme inhibitors and progression of nondiabetic renal disease. A meta-analysis of patient-level data. Ann Intern Med. 2001 Jul 17; 135(2): 73-87.

70. Ehrhart-Bornstein M, Lamounier-Zepter V, Schraven A, Langenbach J, Willenberg HS, Barthel A, et al. Human adipocytes secrete mineralocorticoid-releasing factors. PNAS. 2003 Nov 25; 100(24): 14211-6.

71. Goodfriend TL, Ball DL, Egan BM, Campbell WB, Nithipatikom K. Epoxy-keto derivative of linoleic acid stimulates aldosterone secretion. Hypertension. 2004 Feb; 43(2): 358-63.

72. Afshinnia F, Wilt TJ, Duval S, Esmaeili A, Ibrahim HN. Weight loss and proteinuria: systematic review of clinical trials and comparative cohorts. Nephrol Dial Transplant. 2010 Apr; 25(4): 1173-83.

73. Ruiz Irastorza G, Espinosa G, Frutos MA, Jiménez Alonso J, Praga M, Pallarés L, et al. Diagnosis and treatment of lupus nephritis. Consensus document from the systemic auto-immune disease group (GEAS) of the Spanish Society of Internal Medicine (SEMI) and Spanish Society of Nephrology (S.E.N.). Nefrologia. 2012; 32 Suppl 1: 1-35.

74. Steinhäuslin F, Wauters JP. Quantitation of proteinuria in kidney transplant patients: accuracy of the urinary protein/creatinine ratio. Clin Nephrol. 1995 Feb; 43(2): 110-5. 